\title{
LEAN CONSTRUCTION IN A SERIOUS GAME USING A MULTIPLAYER VIRTUAL REALITY ENVIRONMENT
}

\author{
Emil L. Jacobsen ${ }^{1}$, Nikolaj S. Strange ${ }^{2}$, and Jochen Teizer ${ }^{3}$
}

\begin{abstract}
Whereas Lean Construction is a state-of-the-art practice in construction, associated simulation games in academic or professional education still rely on manual data input and analysis. Proposed is a digital learning platform that teaches the concept of lean construction using an active, hands-on serious gaming environment involving multiple players simultaneously in virtual reality. The novelty is to share rapid feedback with the participants while playing the game. Findings through testing demonstrate they benefit from the run-time data analysis and more effectively understand lean principles to eliminate waste, allow collaboration, and optimize quality in the value-added building chain.
\end{abstract}

\section{KEYWORDS}

Lean, education and training, multiplayer virtual reality, runtime data, serious gaming.

\section{INTRODUCTION}

Labor productivity in the construction sector has seen little growth over the past decades (Barbosa et al., 2017). To direct necessary change, many possible avenues exist. One is labor productivity-increasing measures. Several other directions range from more effective collaboration among project partners and new contracting options to projectlevel actions, e.g. using emerging technology that optimizes construction operations.

For years, leading construction companies have identified waste in human capital as a prime reason for low productivity in construction. For this specific purpose, simulation games are used to educate project personnel with better results than traditional lectures (Herrera et al., 2019). For example, lean construction principles can be learned in simulating the real-world experience in form of a hypothetical scenario in a serious game (defined as a purpose other than just fun).

While lean construction simulation games assist in the task of aligning the individual project personnel to teams well, for several reasons, they have not become part of a general best practice developed for the construction industry (CII, 1997). One main reason is, playing such simulation games is a resource-intensive task. It: (a) requires often one or a group of experienced lean expert/s with adequate training skills to convey the learning goals and measure accordingly the team's progress; (b) involves typically large scale physical models, which are difficult to set up on the day of training and transport; (c) requires quite some maintenance to replenish individual pieces that are being

1 PhD student, Department of Civil and Architectural Engineering, Aarhus University, Aarhus, Denmark, elj@cae.au.dk, orcid.org/0000-0001-6008-2333

2 MS student, Department of Civil and Architectural Engineering, Aarhus University, Aarhus, Denmark.

3 Associate Professor, Department of Civil and Architectural Engineering, Aarhus University, Aarhus, Denmark, teizer@cae.au.dk, orcid.org/0000-0001-8071-895X 
consumed during the playing, and (d) demand sometimes extensive travel from the trainer(s) or the model to perhaps even foreign countries. In brief, the overall investment in custom-made physical simulation models and their accompanying instructional material easily reaches $10,000 €$ or more. The demand for such models and trainers within an organization can exceed their availability or be too rare to justify the investment. This a reason why lean construction training is often offered by consultants. Not surprisingly, simulation games in lean construction have evolved over time. Benefiting from industry experience, academia has constantly pioneered their next versions.

This is the case here. The proposed concept envisions resolving some of the shortcomings. This paper (1) introduces lean construction principles, (2) reflects upon the use of simulation games in lean construction training, (3) provides the state-of-the-art specifically in multiplayer virtual reality (VR) and serious gaming environments, (4) introduces the design of the developed serious game in multiplayer VR, (5) shows early implementation and results, and (6) gives an outlook and the remaining crucial challenges.

\section{BACKGROUND}

\section{LEAN CONSTRUCTION PRinCIPLES}

Lean in construction was examined as early as 1992. Koskela (1992 and 2000) developed the Transformation-Flow-Value (TFV) theory and Seven Flows, saying that construction can be conceptualized with the transformation of resources and the creation of systematic value and continuous flow of materials and people. Lean production control theories have been emerging for the construction sector since then (von Heyl and Teizer, 2017).

One of the goals of applying lean to construction is to fully understand the dynamics of production, the effects of dependencies, and the variation that occurs along the supply and assembly chains for each project. Because the scope of the projects differs from every project, lean construction uses two major criteria (Aziz and Hafez, 2013): Planning: The defining criteria for success and producing strategies for achieving the end goal; control: The ability to control events so that they conform to the plan and also trigger learning and re-planning. This research seeks to reduce waste. Several lean principles can be applied.

The Flow principle is one of the core elements of Lean Thinking. Flow depends heavily on the quality management of activities. Avoiding rework related to quality deficiencies is essential for assuring that the flow of products is as planned. Another key factor within the flow is the visual transparency of work. Research has shown that visual controls in job sites observed a straight correlation between transparency and efficiency.

The Perfection principle is more of a focus on the learning aspect of Lean. One note of Lean Thinking is the continuous learning and improvement of techniques and methods. Therefore, establishing a systematic procedure to constantly learn and improve the standardisation of work is key by using quality systems and focusing on the characteristics that affect product performance (Cheng et al., 2012).

\section{LEAN THINKING USING SimUlation GaMeS}

Although Lean Thinking intended practical benefits, efficient training tools for lean construction are still emerging. In these, however, it is often humans that gather and assess data during the training event. Humans again are needed to interpret the results and transfer information to valuable knowledge that is finally applied in collaborative learning experiences. The chance for instructor/s to manipulate information in such settings is high.

Example: At least two rounds are played in simulation games. The first round does not and the second round follows lean principles. The performance of the participants in 
both is often compared. The assessment criteria seem strict: total playtime by minutes and seconds (recorded by a manual stopwatch), the number of completed sections (often rooms) by the entire team, the progress made by individual trade, and their number of defects created. While the participants are divided into carrying out trade-specific work tasks, each represents the trade they identify with the most, for example, being a: carpenter, plumber, or electrician. The instructor/s determine any of the potential quality issues based on a-priori set knowledge (previous events) at the end of each play round.

Existing simulation games are often criticized to lack realism, e.g., with construction being depicted by paper airplanes or in miniature format with alternative materials such as marbles or Lego (von Heyl 2015). Dallasega et al. (2020) implement VR in a simulation game, but the segment is still not realistic as the task of building Lego is just transferred to a virtual environment. Furthermore, most games lack data collection as this is handled manually by observers. This can potentially lead to biased data or few data being collected.

While quality issues are often not argued (the serious gaming environment is quite relaxed), as experienced in several runs of academic as well as professional simulation games, instructor/s often give participants the opportunity to take short breaks in the second round. While the clock is then stopped, the participants can re-assess and modify their performance just-in-time. This opportunity, however, is not given to the (same) participants in the first round. This causes two issues: (a) time recordings are not comparable and (b) lessons learned from playing the same simulation game twice (it would be too difficult to have a second, but different model available) improves naturally the performance criteria (participants' learning curve).

Therefore, it is believed that simulation games are tailored towards an expected outcome. Errors occur when the instructor/s presents quantitative data that actually should compare the participants' performance in both rounds objectively. However, it does not.

\section{Tracking Methods for Lean Purposes}

Numerous promising methods exist that link technology to lean construction implementation as well as training. For example, Building Information Modeling (BIM)based scheduling has been tied to scheduling (4D) in lean construction. Sacks et al. (2009 and 2010), in particular, and others (Mollasalehi, 2018; Singhal et. al., 2018; Fosse et al., 2017; Tillmann and Sargent, 2016; Dave et al., 2011, Teizer et al., 2017a) have shown from the earliest concepts to now applications in industry. Other studies (Cheng et al., 2010; Costin et al., 2015; von Heyl and Teizer, 2017; Teizer et al. 2017b; Li et al., 2017) have taken a further step and started integrating technology as an additional enabler for harmonizing the meaningful data sets which exist or can be generated within each of the three silos: BIM, Internet of Things, and Lean Construction. One could call this integration a 'Digital Twin' today, where continuous gathering of performed data on construction sites replenishes as-planned data. By doing so, it results in rapid, objective information that enables control over a project's progress, systematic analysis and forecasting, and communication for informed decision making among collaboratively working teams across all trades. However, while this has become possible in real life, higher education or training environments lack such use of technology.

A critical component for digitalizing simulation games in lean construction is the possibility of seamless data recording. This includes but is not limited to locating construction workers inside of a work environment (in real life) or participants in a lean construction simulation game (here: virtual). While a large body of work in the research literature exists on indoor location tracking - even in combination with BIM (Neges et 
al., 2017; Teizer et al. 2007; von Heyl and Demir, 2019), little of it can be used in lean construction simulation games (Teizer et al., 2020). None can be applied in multiplayer virtual learning environments meant for lean construction (Teizer et al., 2019; Golovina et al., 2019), because players typically traverse in virtuality only.

\section{USE OF VIRTUAL REALITY IN CONSTRUCTION}

Over the past years, the construction industry has increasingly adopted VR solutions (Zhang, et al., 2020). The solutions vary in use, for example, safety training (Golovina et al., 2019; Wolf et al. 2019; Bükrü et al., 2020, Solberg et al., 2020), workspace planning (Getuli et al., 2020), and project walkthroughs (Du et al., 2018). Since construction provides a collaborative environment, a virtual environment that imitates it would allow for better immersion and an experience more true to the construction environment. This could be achieved through a multiplayer virtual environment, which would enable a more realistic setting when compared to the real construction site.

VR is achieved through the implementation of computer technology. A range of commercially available systems have been created for this purpose such as headsets, treadmills, gloves, and controllers (even with forced feedback). These systems allow for the creation of an illusion of reality, which is interactive. Immersive VR technologies, therefore, enable a user to enter a simulated environment with related activities.

In construction, this is usually a construction site scenario based on real-life situations. Michalos et al. (2018) proposed a method that enhances the design of workplaces and supports decision-making processes, through the collection and analysis of the position tracking of a worker. This is facilitated by an immersive realistic VR-simulated environment in which a worker can perform regular tasks. Using this data, the worker's movement and actions can be optimised, thus reducing costs and time concerning the actual physical implementation of the work (Getuli et al., 2020). Delgado et al. (2020) have studied the current research within Augmented Reality (AR) and VR for architecture, engineering, and construction. They have concluded that the adoption level of both AR and VR remains low within the construction sector.

\section{MULTIPLAYER ENVIRONMENTS IN VR}

This paper presents a multiplayer environment, meaning an environment where multiple people can be present at once. Multiplayer environments have not yet been fully explored within a construction VR environment. Only a few papers fully utilize the possibilities the multiplayer environment presents, i.e. Du et al. (2018) who utilize the multiplayer feature in walkthroughs for communication between the designer, contractor, and owner, and Zhao et al. (2020) who research manufacturing simulation with multiplayer functionality. Furthermore, in the scene created by Zhao et al. (2020), the participants do not occupy the same workspace but have dedicated spaces for themselves.

The research related to construction has not yet utilized use-time data collection which is possible to capture through VR as seen in other experiences (Golovina et al., 2019; Solberg et al., 2020). Furthermore, they do not explore multiplayer VR for collaborative work as the work on a construction site usually will be (incl. a site with multiple trades).

\section{Role OF MUltiplayer Virtual Reality}

While no multiplayer VR environments exist that are tailored for a lean construction simulation game, our vision is a hands-on learning in a classroom-style setting that enables active learning. This would follow (not replace) other existing, traditional learning styles, i.e., frontal teaching lectures using presentation slides or small, but very efficient game-plays (e.g., "airplane game"). By today, quite a few well-implemented 
efforts that teach the lean principles using such methods have entered higher education and consulting (Table 1). Many yet do not address parts of the aforementioned issues. While they are called lean simulation games, they follow the objectives of serious games.

Table 1: Examples of lean construction simulation games and categories they address

\begin{tabular}{|c|c|c|c|c|}
\hline $\begin{array}{c}\text { Category } \\
\text { Game }\end{array}$ & $\begin{array}{l}\text { Building } \\
\text { Information } \\
\text { Modeling }\end{array}$ & $\begin{array}{l}\text { Automated data } \\
\text { collection and } \\
\text { processing }\end{array}$ & $\begin{array}{c}\text { Lean } \\
\text { principles* }\end{array}$ & $\begin{array}{l}\text { Virtual } \\
\text { * reality }\end{array}$ \\
\hline${\text { Lean construction simulation game }(\mathrm{s})^{\star *}}^{*}$ & & & $\mathrm{X}$ & \\
\hline Leapcon (Sacks et al., 2007) & & & $X$ & \\
\hline RBL-PHP (Li et al., 2018) & $(\mathrm{X})$ & $\mathrm{X}$ & $x$ & \\
\hline BIM-IoT-LC (Teizer et al., 2020) & $(\mathrm{X})$ & $\mathrm{X}$ & $X$ & \\
\hline Multiplayer Serious Game for Lean Construction & & $\mathrm{X}$ & $\mathrm{X}$ & $\mathrm{X}$ \\
\hline
\end{tabular}

\section{METHOD}

Multiple solutions exist both for multiplayer VR hardware- and software setup. There are several commercially available options for the headset a user wears to experience a VR scene, the controllers a user needs to traverse or interact with objects in a VR scene, and the computers themselves to power and process the setup. Furthermore, several solutions are present for designing and creating a VR game, and even for how to enable multiple participants to be in the same VR environment at once. All is a non-trivial effort, often compared to movie sets in the filming industry (Wolf et al. 2019). The full setup that was created in iterative development stages is seen in Figure 1.

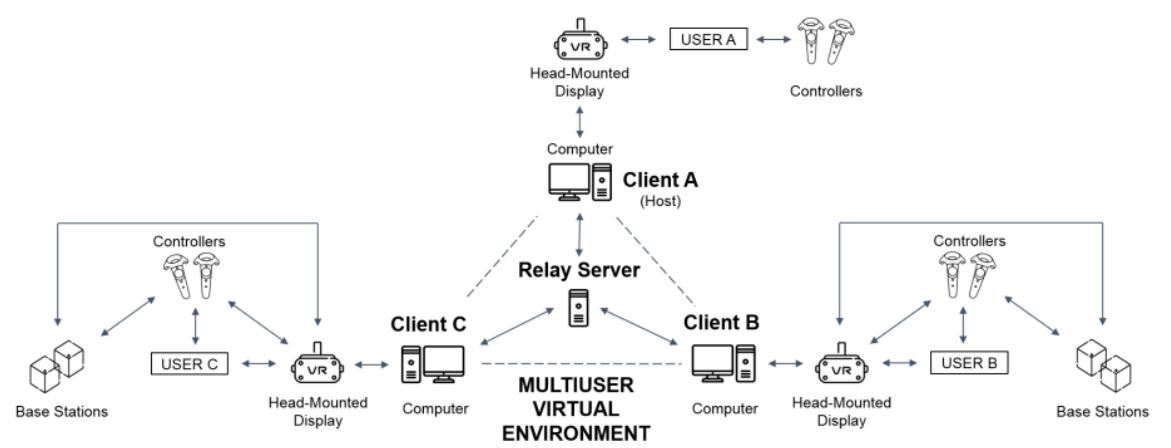

Figure 1: Multiplayer virtual environment for a serious game in lean training

\section{DESIGN OF SCENARIO}

The design includes two scenes (Figures 2a and 2c): A 'messy' scene, which does not follow lean initiatives, and a 'lean' scene where lean initiatives have been incorporated. Both are similar in layout, and at closer look small (but effectful for a participant) differences appear. In the first scene where lean initiatives are not present, the participants are confronted with several problems: (1) They have not been given a location sequence to follow, (2) they have not been instructed in the specific work, only what their task is, and (3) the workstations are not cleaned from obstructions. In the second scene lean initiatives are presented. A location sequence is given, all participants have training for their task, and according to Lean $5 \mathrm{~S}$ principles all workstations are free from obstructions. Each round is designed to last under 30 minutes for reasons of learning effectiveness.

Each scene has three workstations and one panel area with a board used for instructions Figure 2b. When participants join the game, they are placed in the central 
part of the selected scene, in front of the (lean) instructions board. There it is possible to see both instructions for the tasks for the 3 trades (carpenter, plumber, and electrician) and their live work status. Latter is shown via cubes placed according to the workstation the trade is currently working in. The carpenter has to place 6 drywall sheets in 4 different sizes (Figure 3a-d). The plumber has to place 4 different pieces of pipes, 1 sink, and 1 toilet. The electrician has to place 2 lamps and 2 wires of the same kind. All the objects are part of automatic data collection which is used for the analysis of the game.
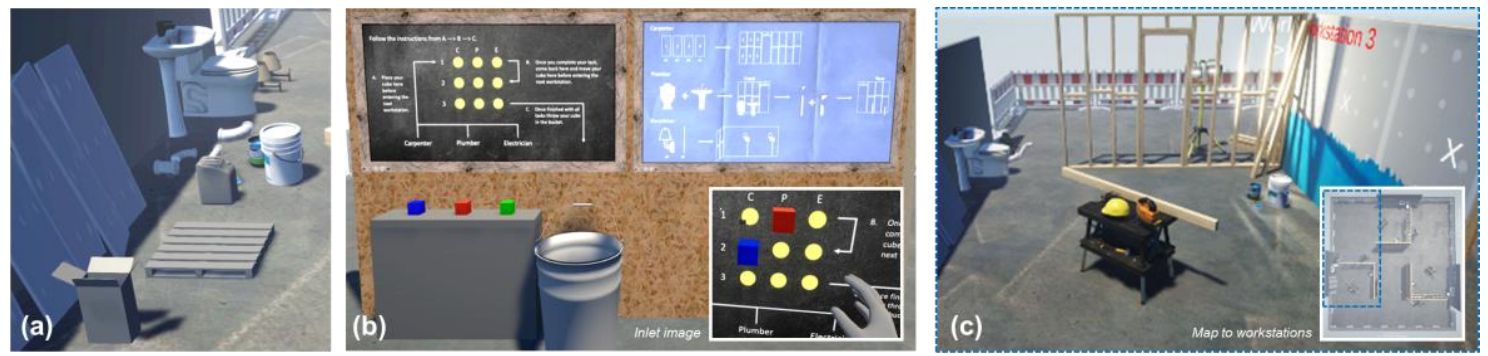

Figure 2: (a) Workstation in 'messy' state, (b) board with instructions (incl. display which workstation a trade occupies at a given time; assembly sequence of parts; small desk with 3 cubes indicating that trades are in a waiting position; bucket that trades use to throw their cube in after they completed all work tasks; the inlet image shows the live

status of the display during a scene play), and (c) a workstation in its 'lean' state

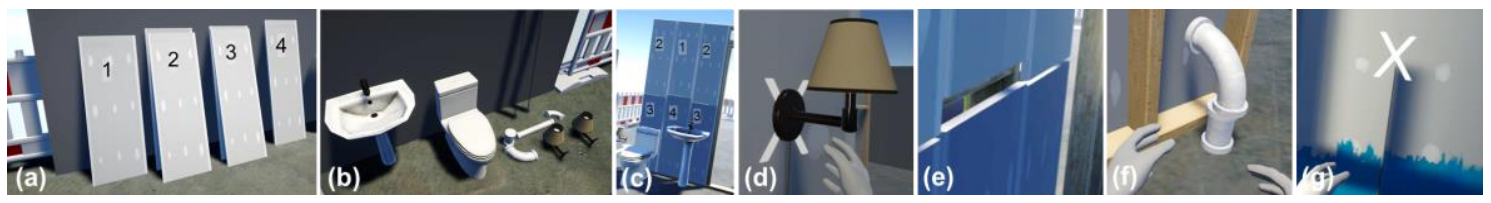

Figure 3: (a-b) Material sorted, (c-d) correctly installed by trades, (e-g) examples of observed quality issues, e.g. gaps in installed drywall sheets, misaligned pipe fitting, and lamp installation missing

\section{HARDWARE SETUP}

The research was conducted using two different types of VR headsets to display the possibility of cross-brand usability. The setup included two HTC Vive Pro Eye headsets (of which the eye-tracking functionality was not used) and one Oculus Quest 2 headset. The controllers being used were standard controllers shipped with the headsets and both the HTC Vive headsets were connected to two base stations respectively. All headsets were connected to computers, which were used as engines for running the game.

\section{SOFTWARE SETUP}

For the game engine, there are several options, amongst others Unity3D and Unreal Engine. Unity3D (version 2019.4.8f1) was used for the project and all scripts that enabled the game to run were written in $\mathrm{C \#}$ as this is one of the two programming languages that Unity3D supports. For movement and interactions, the XR Interaction Toolkit (Unity, 2020) was used for the framework. This allowed for cross-brand experiences, which was necessary, because of the two different brands of headsets being used.

PUN 2 from Photon (Photon, 2020) is used as the integration that allows for the development of multiplayer experiences (the server connecting Clients $\mathrm{A}, \mathrm{B}$, and $\mathrm{C}$ ). With Unity, the host will have complete control over the game, i.e. when he leaves the scene, the game will end. With Photon, the host is only seen as another client. This allows for greater performance, as fewer steps are required to transfer data between the clients. 
This setup is especially useful as this allows participants to connect from anywhere and will work on networks that have restrictions regarding peer-to-peer connectivity. Furthermore, this setup allows for easy setup if the experiment is conducted in a different location, as it is not reliant on the IP addresses and without the need for reconfiguration.

\section{Data Collection}

For the experiences in VR, automatic data collection has been set up. This allows for quantitative analysis of the runs and makes it possible to see potential optimizations, which in the end could allow users to optimize the workflow on real construction projects. The data collection happens when interactions with objects happen. All interactions are recorded in a CSV file. The contents are shown in Table 2.

Table 2: Data types and their meaning

\begin{tabular}{cccccc}
\hline Data type & Timestamp & Object & Location & Action & Trade \\
\hline Description & Time of action & Object & Location of & Type of action & Who interacted \\
& [hh:mm:ss] & interacted with & interaction & [Pick-up, & [Carpenter, Plumber, \\
& [e.g., sink, pipe] & [WS1 to 3] & Place] & Electrician] \\
\hline
\end{tabular}

\section{RESULTS}

Similar to simulation games for lean construction involving a physical model, two rounds were played to be able to display the impact of lean when compared to experiencing a workplace without lean initiatives. The automatic data recording is being used in both scenes to be able to compare them afterward.

The first round took the 3 participants 12 minutes and 16 seconds to complete. They combined had 29 occasions of multiple material handlings, which refers to the number of times a participant had to handle an object more than needed. An example, is dropping material and picking it back up again, or relocating it to its final installation point. Even with the 29 steps of rework, there still were 5 quality issues observed during the first round. These were found upon inspecting the data that relates to quality issues (incorrectly placed objects trigger a counter). This later was verified by analysing additional video footage of cameras installed throughout the scene and the participants' field-of-view recordings. Examples of these quality issues can be seen in Figure 3e-g.

The second round took $6 \mathrm{~min}$ and $56 \mathrm{sec}$ to complete and had 11 occasions of multiple material handling (62\% decrease) and ended up with only 1 quality issue ( $80 \%$ decrease). This already shows an improvement between the two scenarios. Because of the automatic data collection, it is possible to look at data for every workspace and thereby examine why the lean round was significantly faster. Figure 4 shows the comparison.

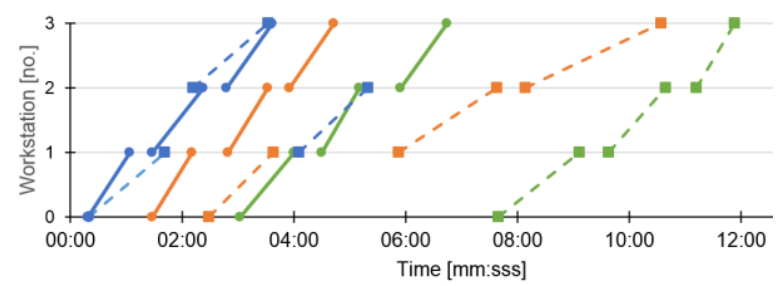

Figure 4: Location-based schedule of 'messy' (dashed) vs. 'lean' scene (solid lines)

The 'lean' version (solid lines) is faster than the non-lean ('messy') version (dashed lines). Overall, the duration is cut roughly into a bit more than half (57\%). Another indication is the slope of the lines. When the slope is steep (vertical lines), the task is done faster. Here, especially the carpenter and the plumber (orange colour) performed faster. This can be due to several things, the most significant being the mess that needs to be cleaned before 
starting their work in the 'messy' scene. This could also be a reason why the electrician (green colour) did not have as much improvement as the other two trades, as the slope difference between the green solid lines and green dashed lines was not as significant as the other trades. This is because this trade did not need to move objects before starting the assigned task. Besides the slope, it is also seen that the carpenter went from workstations 1 to 3 directly instead of following the sequence: 1 to 2 , and then to 3 . This made the plumber wait after workspace 1 and thereby delaying the whole team.

The 'lean' scene was played as the last. This meant that all participants were already experienced in this environment, which also could affect the performance of the second round, both in terms of the time of completion but also in terms of quality as described earlier. Eventually, multiple different environments with various tasks will remedy such issues, or additional participants not used to either scene will be used for more objective comparison. These limitations can be uplifted, but should not diminish the benefits the developed serious game using a multiplayer virtual reality environment generated and once results are compared to existing simulation games used in lean construction training.

\section{CONCLUSION}

This research successfully developed a serious virtual reality (VR) multiplayer game to teach lean construction. The preliminary findings show high potential for use-time data collection for a thorough analysis of several lean principles, such as the flow principle and the perfection principle. The results also show how a VR experience can be used to teach lean principles in a more realistic environment than board or other lean simulation games and that it can help in decision-making processes by the use of data collection and analysis. The developed tool is more sensitive to the overall investment, and also allows for teaching these principles while participants are apart, e.g., under Covid-19 restrictions.

The study is one of the first attempts to examine multiplayer environments for construction. It has shown potential for improvement. For example, giving participants with little to no prior VR experience additional training or distinguishing the layout and tasks in the two rounds more. Future versions would also benefit from implementing additional lean principles (e.g., the pull principle where a warehouse functions as the central hub for the material). For data collection, it should be showcased if participants were helping each other with tasks. Their trajectory tracking should be recorded to further optimize the workflow through data analysis and presentation between the two game scenes. Using a larger sample size and video footage recorded of the participants outside of VR would allow for better data analysis, incl. which impact emotional reactions and mistakes of participants have when learning with VR. While a study of VR sickness was not part of the research scope, its limitation should be investigated in a future study. The same counts for protecting the participants' privacy rights. The individual analysis would then allow personalized feedback for their performance, as it is a training environment.

This game currently is limited to ten participants that join the server application. More tasks could be added and modelled in Unity3D to allow for more realistic workflows typical in construction. This, however, requires additional VR headsets and computers, which come at higher expenses. The investment may return value for other AEC purposes.

\section{REFERENCES}

Aziz, R. \& Hafez, S. (2013). "Applying lean thinking in construction and performance improvement.” Alexandria Eng. J. 52(4), 679-695, doi.org/10.1016/j.aej.2013.04.008. Barbosa, F. (2017). “A Route to Higher Productivity.” McKinsey\&Company. 
Bükrü, S., Wolf, M., Böhm, B., König, M., \& Teizer, J. (2020). “Augmented Virtuality in Construction Safety Education and Training." EG-ICE, Berlin, Germany, 115-124.

Cheng, T., Yang, J., Teizer, J, \& Vela, P.A. (2010). “Automated Construction Resource Location Tracking to Support the Analysis of Lean Principles." 18th IGLC, 643-653.

Cheng, T., Mantripragada, U., Teizer, J. \& Vela, P.A. (2012). "Automated Trajectory and Path Planning Analysis Based on Ultra Wideband Data", Computing in Civil Engineering, 26(2), 151-160. doi.org/10.1061/(ASCE)CP.1943-5487.0000115.

Construction Industry Institute. (1997). "Team Alignment During Pre-Project Planning of Capital Facilities - RR113-12." The University of Texas at Austin.

Costin, A.M., Teizer, J., \& Schoner, B. (2015). "RFID and BIM-enabled worker location tracking to support real-time building protocol and data visualization." Information Technologies in Construction (ITCON), 20, 495-517.

Dallasega, P., Revolti, A.,Sauer, P.C., Schulze, F. \& Rauch, R. (2020). "BIM, Augmented and Virtual Reality Empowering Lean Construction Management: A Project Simulation Game." Pro. Manfct. 45:49-54. doi.org/10.1016/j.promfg.2020.04.059.

Du, J., Shi, Y., Zou, Z., Dong, Z. (2018). "CoVR: Cloud-Based Multiuser Virtual Reality Headset System for Project Communication of Remote Users.” C. Eng. Mgmt., 144.

Delgado, J.M.D., Oyedele, L., Demian, P. \& Beach, T. (2020). "A research agenda for augmented and virtual reality in architecture, engineering and construction." Adv. Eng. Inf., 45101122.

Dave, B., Boddy, S. \& Koskela, L. (2011). "Visilean: Designing a production management system with Lean and BIM." 19th IGLC, Lima.

Fosse, R., Ballard, G. \& Fischer, M. (2017). "Virtual Design and Construction: Aligning BIM and Lean in Practice". 25th IGLC. Heraklion, Greece, 499-506.

Golovina, O., Kazanci, C., Teizer, J. \& König, M. (2019). "Using Serious Games in Virtual Reality for Automated Close Call and Contact Collision Analysis in Construction Safety." 36th ISARC, doi.org/10.22260/ISARC2019/0129.

Getuli, V., Capone, P., Bruttini, A. \& Isaac, S. (2020). "BIM-based immersive Virtual Reality for construction workspace planning: A safety-oriented approach." Aut. in Constr., 114103160.

Herrera, Rodrigo F., Sanz, M. Amalia, Montalbán-Domingo, Laura, García-Segura, Tatiana \& Pellicer, Eugenio. (2019). "Impact of Game-Based Learning on Understanding Lean Construction Principles", Sustainability, 11, 5294.

Koskela, L. (1992). "Application of the new Production Philosophy to Construction", CIFE Technical Report \#72, CIFE, Stanford University.

Koskela, L. (2000). "An Exploration Towards a Production Theory and its Application to Construction", VTT, Finland.

Li, X., Shen, G.Q., Wu, P. \& Fan, H. (2018). "RBL-PHP: simulation of lean construction and information technologies for prefabrication housing production", J. Mgmt. in Eng., 34(2), 4017053.

Michalos, G., Karvouniari, A., Dimitropoulos, N., Togias, T., et al. (2018). "Workplace analysis and design using virtual reality techniques." CIRP Annals. 67 (1), 141-144.

Mollasalehi, S., Aboumoemen, A.A., Rathnayake, A., Fleming, A., \& Underwood, J. (2018). "Development of an Integrated BIM and Lean Maturity Model." 26th IGLC, 1217-1228.

Neges, M., Wolf, M., Propach, M., Teizer, J., Abramovici, M. (2017). “Improving Indoor Location Tracking Quality for Construction and Facility Management." 34th ISARC. Photon. (2020) "Photon PUN" https://www.photonengine.com/pun (Jan. 20, 2021). 
Unity Technologies. (2020). "Unity-XR Interaction Toolkit." https://docs.unity3d.com/Manual/com.unity.xr.interaction.toolkit.html (Dec. 10, 2020).

Sacks, R., Esquenazi, A., \& Goldin, M. (2007). "LEAPCON: Simulation of lean construction of high-rise apartment buildings." J. Const. Eng. Mgmt., 133:7, 529-539.

Sacks, R., Dave, B., Koskela, L., \& Owen, R. (2009). "Analysis Framework for the Interaction Between Lean Construction and Building Information Modeling." 17th IGLC, 1-10.

Sacks, R. Radosavljevic, M., \& Barak, R. (2010). "Requirements for building information modeling based lean production management systems for construction." Aut. in Constr., 19(6), 641-655.

Singh, G.R. (2019). "Raywenderlich". https://www.raywenderlich.com/1142814introduction-to-multiplayer-games-with-unity-and-photon. (Jan. 19, 2021).

Singhal, N., \& Ahuja, R. (2018). "Can BIM furnish Lean benefits - an Indian case study." 26th IGLC, 90-100.

Solberg, A., Hognestad, J. K., Golovina, O., \& Teizer, J. (2020). “Active Personalized Training of Construction Safety Using Run Time Data Collection in Virtual Reality." 20th CONVR, pp. 19-30. Middlesbrough, UK: Teesside University Press.

Tillmann, P., \& Sargent, Z. (2016). "Last Planner \& BIM Integration: Lessons from a Continuous Improvement Effort." 24th IGLC, Boston, 113-122.

Teizer, J., Lao, D., \& Sofer, M. (2007). "Rapid Automated Monitoring of Construction Site Activities using Ultra-Wideband." 24th ISARC, Cochin, India, 23-28.

Teizer, J., Melzner, J., Wolf, M., Golovina, O., \& König, M. (2017a). “Automatisierte 4D-Bauablaufvisualisierung und Ist-Datenerfassung zur Planung und Steuerung von Bauprozessen. [Automating Lean Management]" Bauingenieur, Springer, 129-135.

Teizer, J., Wolf, M., Golovina, O., Perschewski, M., Neges, M., \& König, M. (2017b). "Internet of Things (IoT) for Integrating Environmental and Localization Data in Building Information Modeling (BIM)." 34th ISARC, doi.org/10.22260/ISARC2017/0084.

Teizer, J., Wolf, M., \& König, M. (2018). "Mixed Reality Anwendungen und ihr Einsatz in der Aus- und Weiterbildung kapitalintensiver Industrien." [Mixed Reality in Construction Education] Bauingenieur, 73-82.

Teizer, J., Embers, S., Golovina, O., \& Wolf, M. (2020). “A serious gaming approach to integrate BIM, IoT and Lean Construction in Construction Education." Construction Research Congress 2020, Tempe, USA.

von Heyl, J. (2015). "Lean Simulation in Road Construction: Teaching of Basic Lean Principles", 23rd IGLC, Perth, Australia, 403-412.

von Heyl, J. \& Teizer, J. (2017). "Lean Production Controlling and Progress Tracking using Digital Methods." LC3, Heraklion, Greece, 127-134.

von Heyl, J. \& Demir, S.-T. (2019). "Digitalizing lean construction with building information modeling." 27th IGLC, Dublin, Ireland, 843-852.

Wolf, M., Teizer, J., \& Ruse, J.H. (2019). "Case Study on Mobile Virtual Reality Construction Training." 36th ISARC, Banff, Canada.

Zhang, Y., Liu, H., Kang, S., \& Al-Hussein, M. (2020) "Virtual reality applications for the built environment: Research trends and opportunities." Aut. in Constr., 118103311.

Zhao, R., Aqlan, F., Elliott, L.J, \& Baxter, E.J. (2020). "Multiplayer Physical and Virtual Reality Games for Team-based Manufacturing Simulation”. ASEE Conf., 1-2-34989. 